service of a permanent character, since a matter of such importance is to be decided. There would seem to be every reason for an agreement on some standardized test which would prevent any candidate from passing in one form of test, spending years, perhaps, in training and then failing to pass a more drastic test in the end.

The assumption of responsibilites which a person is unfitted to bear is a grave mistake both on the part of the person himself, and those who allow him to do so. But if a test is strict it must be also just; the real disadvantage of cheap and untried tests is their variability. It is here that the chief possibility of injustice in colour vision testing is to be found. It looks, as if it should be easy to obtain a durable and consistent test; actually it takes a very great deal of care to make one. The present Lantern is an effort in that direction.

I am indebted, as before, to those whose help was acknowledged in the previous paper, and in addition to $\mathrm{Mr}$. $\mathrm{H}$. V. Walters for measuring the transmission of some of the filters ; also to Dr. Graves Pierce for the help mentioned above.

\title{
REFERENCES
}

MARTIN, Brit. Jl. Ophthal., Jan. 1939.

Wright (1941).-Proc. Phys. Soc., Vol. LV, p. 93.

\section{GLIOMA OF THE RETINA. A REVIEW OF TWELVE CASES*}

BY

W. B. E. MCCREA

DUBLIN

THIS communication is a clinico-pathological study, based on the twelve patients suffering from the so called glioma of the retina, treated in the Royal Victoria Eye and Ear Hospital, during the years 1938-42 inclusive. To clarify our ideas at the outset, it seems worth while to have some form of classification. I have followed that suggested by Sir Stewart Duke-Elder in his text-book. As he points out, in the present state of our knowledge, any classification can only be of a provisional nature. The divisions of the group are as follows :-

(a) Retinoblastoma-corresponding to the medulloblastoma of the brain. These comprise the great majority of "gliomata."

Received March 13, 1943. Read at Dublin Ophthalmological Society. February 24, 1943. 
Owing to the embryonic nature of the cells malignancy is high. They most often arise from the inner nuclear layer and next most often from the ganglion cell and nerve fibre layers.

(b) Neuro-epithelioma - they are composed of primitive spongioblasts. The external nuclear layer is the usual point of origin. In the pure form they may arise from the ciliary processes. These growths show rosette formation, the presence of which is evidence of partial differentiation into rods and cones. In consequence a somewhat lower malignancy is found.

(c) Medullo-epithelioma-are very rare. They arise from the ciliary epithelium - the place where the medullary epithelium of the primitive neural tube persists in almost undifferentiated form.

(d) Neurocytoma - a few tumours have been described with their cells differentiated as neuroblasts or neurocytes.

(e) Astrocytoma-arises from true glial tissue, and for it the term glioma ought properly to be reserved. It is common in the brain, but surprisingly rare in the eye, since astrocytes are plentiful in the retina. The tumour appears in the second or third decades of life. The first two groups are, of course, relatively common, the last three exceedingly rare.

CASE I. Bilateral retinoblastoma-orbital extension-death.Edward P., was admitted in August 1937 when aged 1 year, under the care of Mr. L. E. Werner. A " glioma" of the right eye was present and the eye was removed on August 26. There was a suspicious looking mass in the left fundus and in consequence it was decided to implant two radon seeds on the sclera.

These were left in position for 8 days. The patient was discharged on November 8 . On December 15 the child was readmitted with a fungating mass protruding from the left socket. The left globe was removed and the orbit exenterated. He received radium treatment. He died in March 1938.

The pathological exhibit in this case is a section of a piece of tissue taken from the left orbit, the globe unfortunately not being available for study. The section shows a very vascular piece of tissue, covered by epithelium, under which there is tumour cell infiltration in places. Then comes an area of elastic and hyaline tissue containing in its deeper layers some retinoblastoma cells. Deep to this is an area of tumour cells, arranged in masses and columns in an irregular fashion, supported by a rather delicate elastic and hyaline tissue matrix. There is a plentiful supply of blood vessels. The cells on the whole are rather larger than those usually found within the globe in tumours of this kind. They have a large circular nucleus staining well, and a very small cell body, polygonal or circular in shape. Necrotic areas so characteristic of retinoblastomata within the globe, are absent. 


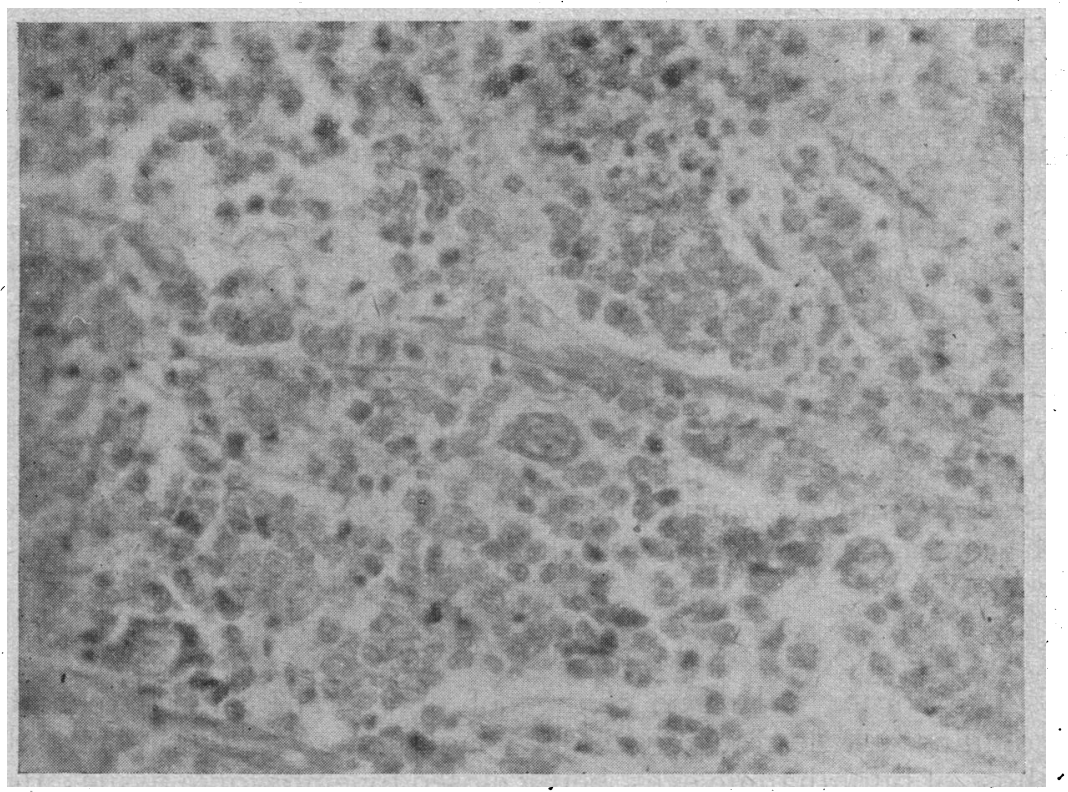

CASE I.

Section through piece of orbital tissue showing retinoblastoma cells.

CASE II. Unilateral retinoblastoma with invasion of nerve head, orbital extension-death.-Mary D., was admitted on July 7, 1938, to hospital under the care of Dr. E. M. Maxwell. She was then aged 2 years and 9 months. About 7 months previously the mother noticed a "golden speck" in the left eye. There were seven children in the family, all of whom were healthy.

A " glioma retinae" was diagnosed and the left eye excised on July 15. The socket was treated by Dr. Stumpf at Baggot Street Hospital. On July 28 she was discharged with instructions to return in 3 months. She was lost sight sight of until March 14, 1939. There was then present a hard mass in the orbit; biopsy showing " glioma" cells to be present. "She was seen by Dr. R. H. Micks, on April 4, when she had a pulse of 60 and neck rigidity. A consultation with Mr. A. A. McConnell was advised, but the mother refused to consider any further operative treatment. On April 10 she was discharged. She died six weeks later.

\section{Microscopic}

Except for some blood vessels lying under the epithelium the cornea is normal. The anterior chamber is also unchanged. The 
iris and ciliary body are markedly atrophied. The entire globe from the posterior aspect of the iris and pars plicata of the ciliary body, is filled with retino-blastoma cells. Much of it is necrotic. The retina is completely destroyed. The optic nerve head is also invaded by the tumour. At one point in the choroid near the ora serrata early calcareous changes are present.

CASE III. Retinoblastoma-uniocular-recovery. Optic nerve free of involvement.-Clement G., aged 2 years, was admitted December 13, 1938, under Dr. E. M./Maxwell. There was a history of a yellow mass seen in the left eye for three months.

There are 13 children in the family; all normal.

With the exception of myopia in the father and the children, the ocular history is devoid of interest. In a letter dated February 1, 1943 , the mother reports the boy as being very well, i.e., just over 4 years after removal of the eye-December 16, 1938.

\section{Microscopic}

The cornea shows no change of note. The anterior chamber contains a little finely, granular coagulum. The angles resemble those of buphthalmic eyes, being closed by embryonic tissue. Both iris and ciliary body are atrophied. The vitreous chamber is filled almost entirely with tumour, small groups of cells extending up to the back of the lens. Small portions only of the retina remain undestroyed; but here and there the origin from both inner and outer nuclear layers can be made out. The characteristic arrangement of a retino-blastoma is present, active, deeply staining cells, arranged about a central blood vessel, are to be seen, intermingled with poorly staining, necrotic cells. A few small haemorrhages are present. Some islets of commencing calcareous change are present, but are few and inconspicuous.

Sections through the cut end of the optic nerve show it to be free of involvement.

CASE IV. Uniocular retinoblastoma, invasion of optic N.outcome untraced-presumed dead.-Gabriel H., aged $2 \frac{1}{2}$ years, was admitted September 22, 1939, under the care of Mr. A. J. Mooney, who diagnosed a glioma retinae in the left eye. The globe was removed September 23. Healing was uneventful and he was discharged September 29. Unfortunately the family have changed their home and it has been impossible to trace the patient.

\section{Microscopic Examination}

The cornea is normal. The iris is atrophic and there is ectropion uveae. The ciliary body is also atrophied. Except for some 
granular coagulum, the anterior chamber is empty. The vitreous chamber is filled with tumour cells extending right up to the back of the lens and the suspensory ligament. It is a very active looking retino-blastoma, the cells being grouped about a central vessel in the usual manner. Among these are necrotic areas and small haemorrhages. There are a few calcareous nodules. The growth is of the endophytum type. It appears to arise chiefly from the inner nuclear layer of the retina, but in places it can

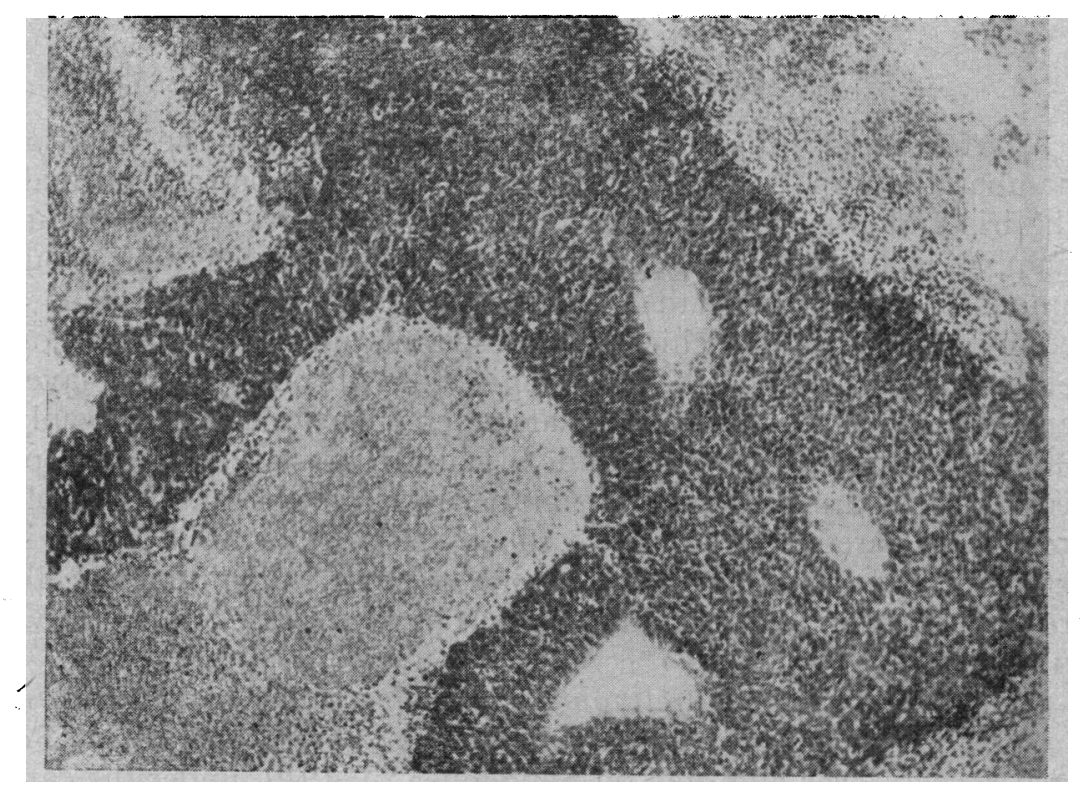

Case IV.

Showing retinoblastoma cells surrounding a central blood vessel. A large necrotic area also appears in the section.

be seen to arise from the outer layer also. The choroid is extensively invaded on one side in the neighbourhood of the ora serrata. A blood vessel traversing the sclera in the equatorial region contains tumour cells. The optic nerve is extensively invaded right up to the cut end.

In the light of the microscopic findings this case could probably be included among the fatal ones.

CASE V. Uniocular retinoblastoma-well, $3 \frac{1}{2}$ years later.' Invasion of optic nerve as far as lamina cribrosa.- John F., aged $4 \frac{1}{2}$ years, was admitted under the care of Mr. F. Lavery on September 28, 1939. He is an illegitimate child, so that family and personal 
history are necessarily curtailed. He has been with a foster mother since he was 11 months old. The latter did not notice anything wrong until the child was just $4 \frac{1}{2}$ years old, when the left eye was seen to squint and a white gleam was noticed in the pupil. There was a history of a fall 4 months previously. On examination a white mass with blood vessels on the surface, involving most of the retina, was seen.

On October 5, the left eye was excised and a glass ball implanted. He was seen in February 1941, March 1942 and February 1943 , the findings on each occasion being normal.

\section{Microscopic Examination}

Apart from a little finely granular coagulum in the anterior chamber the appearances of the cornea and chamber are normal. The iris and ciliary body show little or no atrophy. The vitreous chamber is filled in its posterior $\frac{3}{4}$ with tumour cells and albuminous coagulum "beneath a completely detached retina. It is a retino-blastoma arising chiefly from the inner nuclear and ganglion cell layer, but here and there an origin from the outer nuclear layer can be made out. The typical arrangement of masses of deeply staining cells arranged around a central vessel, and areas of necrotic cells are present. Haemorrhages are absent. A couple only of calcareous nodules are to be seen. The optic nerve is extensively involved up to the lamina cribrosa. The tumour cells are just starting to break through, but have not reached the nerve outside it.

CASE VI. Bilateral retinoblastoma-death 10 months later. Both optic nerves involved outside lamina cribrosa.-Mary A.S., aged 2 years, was admitted on September 25, 1940, under the care of $\mathrm{Mr}$. A. J. Mooney. The history given was that the right eye was noticed to be abnormal at 1 year and 7 months old. There are three other children in the family, all healthy and with good sight. The parental history, on both sides, is negative. On account of the staphylomatous, painful condition of the eye it was removed, the patient being discharged after an uneventful convalescence on October 11. Re-admission took place on April 19, 1941, when a retinal tumour was found to be present in the left eye. This globe was excised and deep X-ray treatment given at St. Anne's Hospital. Death took place on July 22, 1941.

\section{Microscopic Examination}

Right Eye.-This globe is staphylomatous, measuring anteroposteriorly $28 \mathrm{~mm}$. and in the equatorial region $21 \mathrm{~mm}$. The 


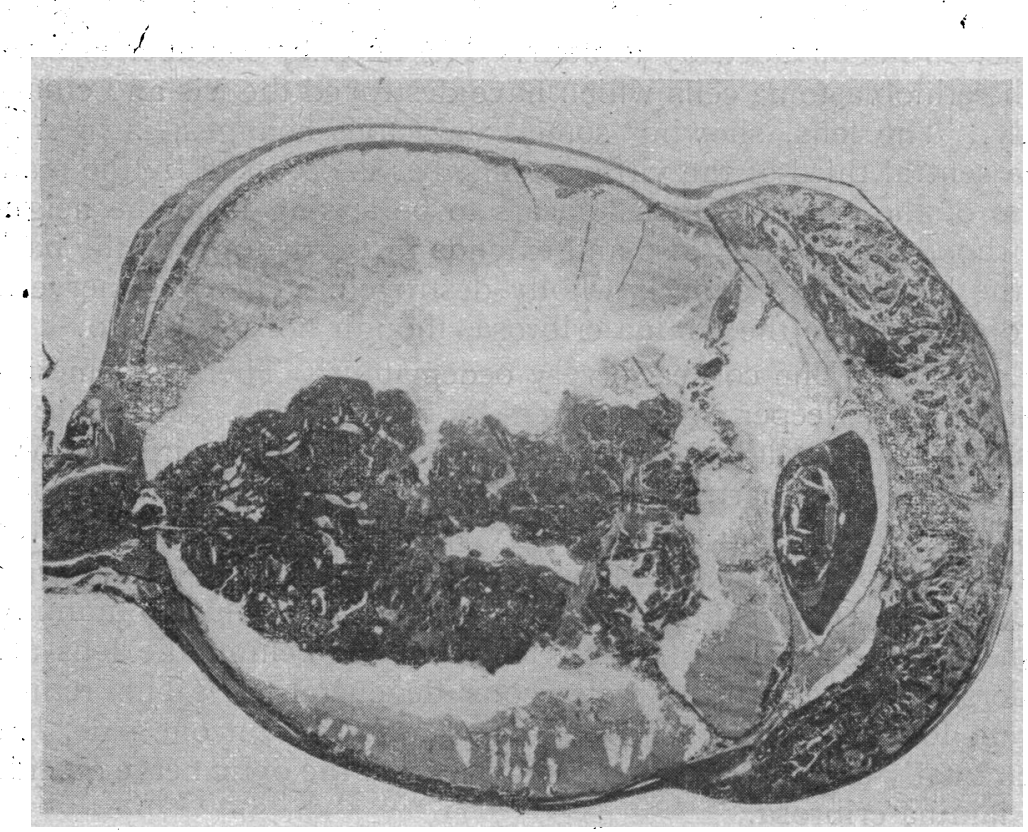

Case Vi. Right eye

Showing staphylomatous globe and anterior chamber full of growth.

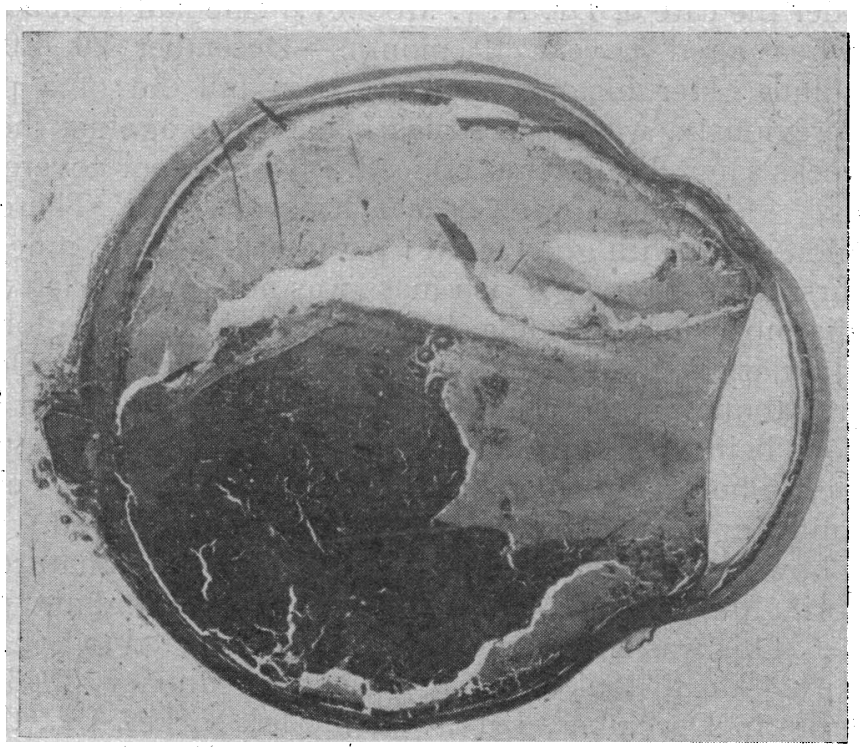

Case Vi. Left eye

Shows invasion of deeper corneal layers by tumour cells. 
cornea is not invaded by tumour. The anterior chamber is filled with retinoblastoma cells which have destroyed the iris and ciliary body. The lens, showing some cataractous changes, is in situ. The central third of the vitreous chamber is occupied by the main mass of the growth which appears to be arising from the neighbourhood of the optic disc and extends forwards towards the back of the lens. The retina is wholly destroyed. The optic nerve is involved outside the lamina cribrosa, though not grossly so.

Left Eye.-The cornea is very oedematous. There is some invasion of the deeper corneal layers by tumour cells. The anterior chamber contains a large amount of cell growth. The iris is represented only by a narrow strip of fibrous tissue. The ciliary body has been completely infiltrated by growth. Three-fifths of the vitreous chamber is occupied by the main mass of the retinoblastoma and the remainder is filled by an albuminous coagulum containing numerous "satellites." Necrotic areas just behind the lens are undergoing commencing calcareous degeneration. The retina, except for a small area close to the ora serrata on one side, has been totally destroyed. There is invasion of the optic nerve outside the lamina cribrosa.

CASE VII. Retinoblastoma-bilateral-death 9 years after first eye involvement, Second eye (i.e., R.E.) optic nerve involved up to cut end.-Maureen O'C., aged 8 years, was admitted April 23, 1941 , under the care of Dr. A. J. Mooney. She had been admitted before when aged 1 year 10 months-December 20, 1934-to this hospital. Her history then was of a fall out of a pram 4 months previously, when she struck her left eye against the kerb. Seven weeks later the parents noticed a " grey spot covered with red veins." She had always been a healthy child. There are 6 other children, all with good sight : parental history also negative. On her first admission a greyish mass was noted in the left fundus and a diagnosis of "glioma" retinae made. The globe was excised January 5, 1934, healing being uneventful. In October, 1939 , Dr. Mooney noted a large yellow mass in the retina below, the vitreous being full of cells. A diagnosis of glioma or tubercle was made. She was given radium for six weeks and in February of the following year she was noted as being improved. Unfortunately however the regression was of a temporary nature only, for in April, 1941, she was admitted again with a blind and painful right eye. This was enucleated and she was referred to St. Anne's for therapy. Death took place at the end of January, 1943. Her father wrote in December, 1942, that the left socket, i.e., the first globe removed, had remained free of trouble. The right, however, he said was causing the trouble. 


\section{Microscopic Examination}

Right Eye.-The cornea is oedematous, both angles are closed by peripheral anterior synechiae. The iris and ciliary body are atrophied. There are numerous scattered tumour cells close to the posterior lens capsule. The retina is almost completely destroyed and the sub-retinal space contains much retinoblastoma tissue,

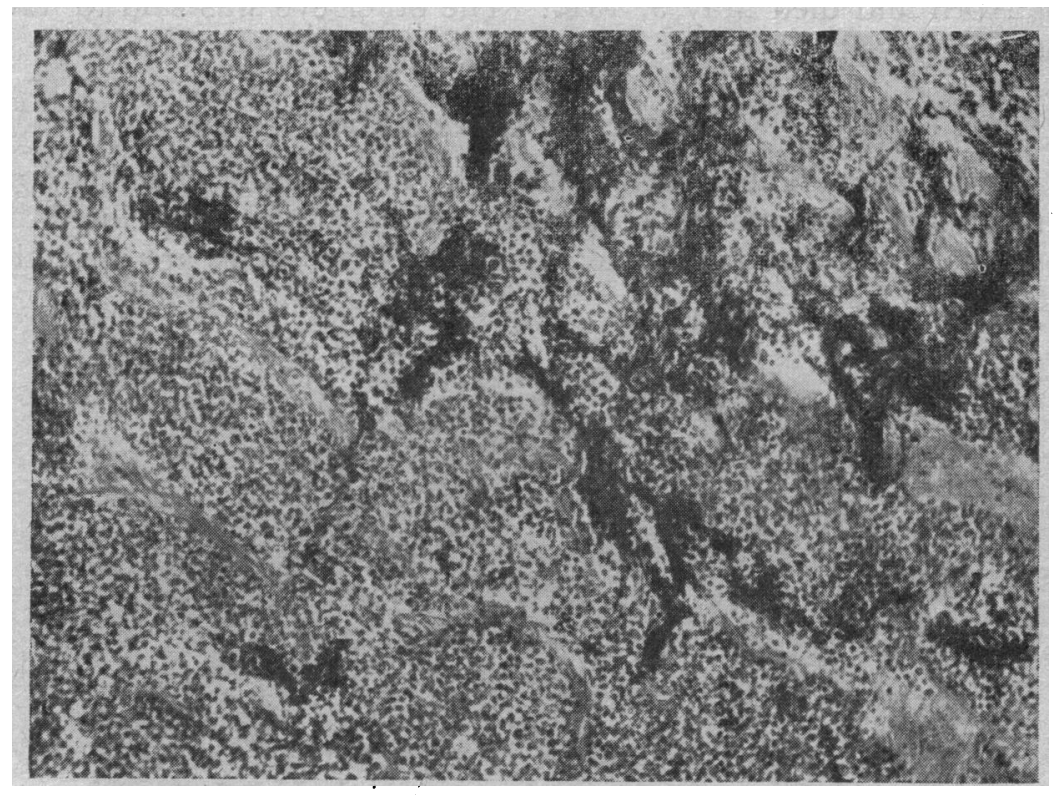

Case VII.

Shows extreme degree of infiltration of optic nerve outside lamina cribrosa.

albuminous exudate and haemorrhage. At one point the choroid is densely infiltrated with cells. Just behind the lens there are numerous small calcareous particles. The optic nerve is densely infiltrated with cells right up to the cut end.

CASE VIII. Retinoblastoma-unilateral-extra-ocular extension, slight involvement of optic nerve, outside lamina cribrosa-death. - Thomas D., aged 3 years, was admitted under the care of $\mathrm{Mr}$. McArevey, December 11, 1941. The history was that the mother noticed a " turn" or " cast " in the right eye at 12 months which grew more pronounced. There are five other children in the family, who are said to have sound eyes. No history of any ocular disease, on either side in the parents, was elicited. 
On ophthalmoscopic examination of the right eye, a large woolley white area extending to the temporal side of the disc with haemorrhage and a retinal detachment below, were seen to be present. On December 18, the R.E. was excised. On January 2, 1942 , the child was sent for deep X-ray to St. Anne's Hospital. The treatment was interrupted by an attack of measles for which he was treated at Cork Street Hospital. On March 27, he was retransferred to St. Anne's. He was sent home towards the end of April and died May 9, 1942. The other eye was said to have been involved.

\section{Microscopic Examination}

Right Eye.-The cornea is normal. The anterior chamber contains some albuminous coagulum. Both angles are closed by peripheral anterior synechiae. Iris and ciliary body are atrophic.

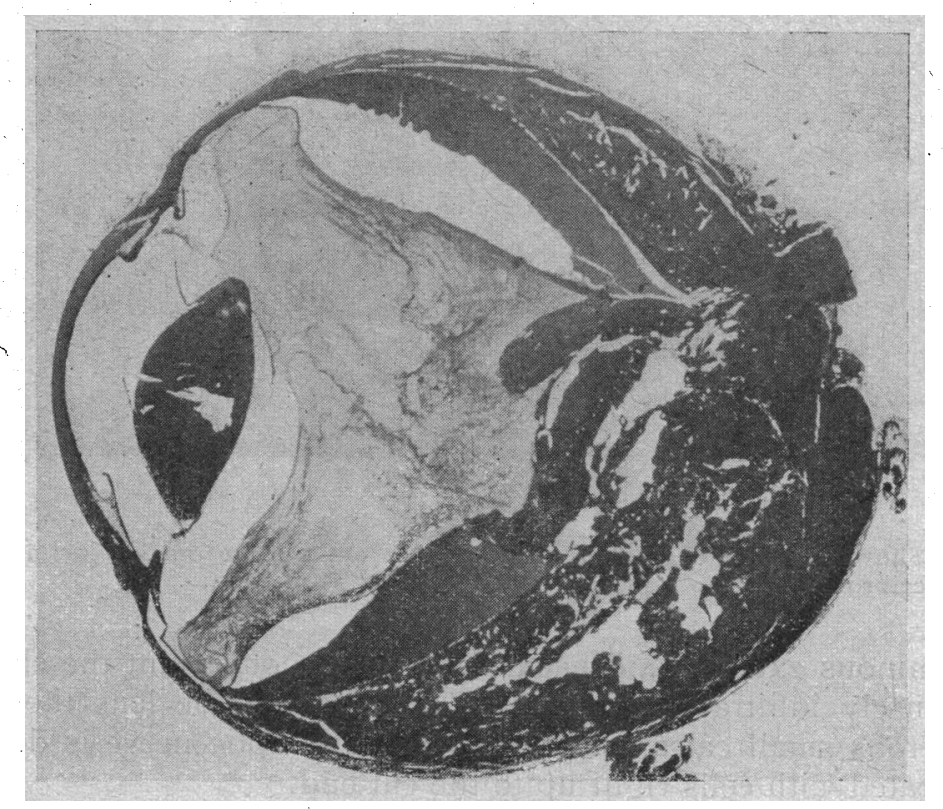

CASE VIII.

Showing extra-ocular extension at the posterior pole.

Arising from the retina in the neighbourhood of the optic disc there is a retinoblastoma-exophytum-which with a considerable amount of albuminous exudate completely detaches the retina. This growth extends to the disc and invades the nerve outside the lamina cribrosa. On one side of the disc between the atrophied 
choroid and the sclera there is a solid mass of tumour which at the edge of the disc infiltrates through the sclera. Outside the. globe in relation to this mass of growth, there is an extra-ocular extension. On the other side of the disc there is a similar cell mass lying between sclera and choroid.

CASE IX. Retinoblastoma-uniocular-no involvement of optic nerve-free of recurrence after 8 months.-Owen K., patient of Dr. McArevey, aged 3 years, was admitted on May 1, 1942. His parents gave a history of his not seeing objects well with the left eye and of having had a " stare" in it from birth. The family history was negative-there are two other children alive and with normal eyes; parents and their relatives are all alive and normal. On examination he was found to have a whitish mass in the left fundus which was diagnosed as a glioma retinae and excision advised. The right eye has a zonular cataract which makes it difficult to state categorically that it is normal. The fundus has been examined repeatedly and seems to be healthy. The child was last seen in January, 1943, and nothing abnormal was noted either in the right eye or in the socket.

\section{Microscopic Examination}

The cornea and anterior chamber do not show any changes of note. The iris and ciliary body are little atrophied. The retina is almost completely detached by an albuminous coagulum in which some isolated retinoblastoma cells are present. The tumour takes

- origin from both outer and inner nuclear layers of the retina. It falls into the category of "glioma" endophytum-occupying about one third of the vitreous chamber. One small calcareous nodule only was found. The optic nerve is free of tumour.

CASE X. Neuro-epithelioma in the left eye, in male aged 67 years. Right eye degenerate-no neoplasm. In good health 8

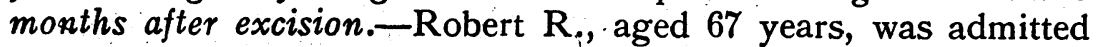
for the first time in February, 1937, under the care of Dr. J. B. McArevey. He was then aged 62. Investigation of personal and family history revealed nothing of note. A posterior cortical cataract was present in R.E. projection was fair, vitreous fluid with gross floaters, no detachment of the retina to be seen. The condition of the left eye at this time was: $V=6 / 60 \mathrm{c}-2.50$ D.sph. $=6 / 24$, incipient cataract, fine vitreous floaters. On March 1, 1937, an intracapsular extraction, with a complete iridectomy, was performed on right eye, going off uneventfully. On March 12, he was noted as having gross vitreous floaters and a retinal detachment. Further treatment was not advised and he was sent out March 17, 1937. He was re-admitted February 26, 1942, when 
the left lens was found to be cataractous-projection inaccurate. Tension (Schiötz) $23 \mathrm{~mm}$. On March 5, 1942, an intracapsular extraction with a complete iridectomy was done. A membrane was seen at this time in the vitreous. The eye remained red and painful, in spite of treatment by N.A.B., sodium salicylate and other procedures.

On April 29, a large hyphaema was present. As the pain persisted and in view of the inaccurate projection it was considered better to excise the globe. This was done on June 10, 1942. In view of the pathological findings in the left eye it was thought wiser to remove the right, which was done September 30, 1942. In February, 1943, the patient reported himself as being in good health.

\section{Microscopic Examination}

Left Eye.-Cornea shows no change of note. The anterior chamber contains a large hyphaema. Both iris and ciliary body are much atrophied. Behind the iris there is an ellipse of compressed, amorphous material, resembling lens material, and surrounding this some loosely arranged vitreous, containing blood. Posterior to this is a completely detached and folded up retina. Behind the

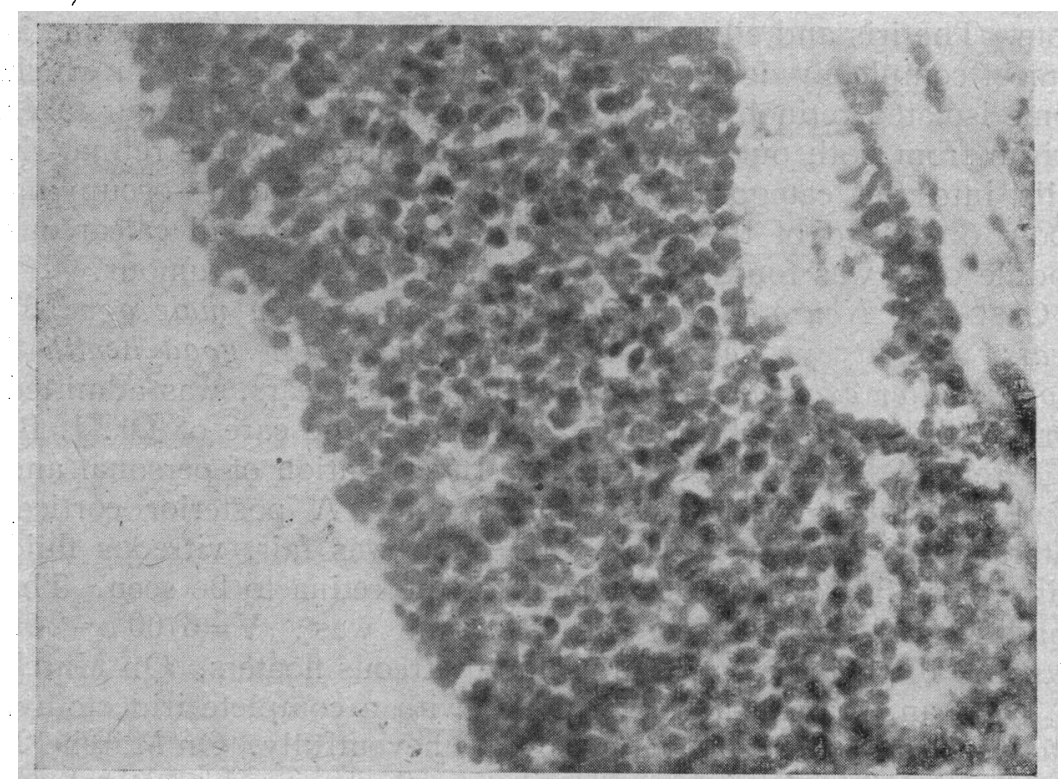

Case X.

Showing rosette formations. 
retina and in relation to the choroid, there is a good deal of albuminous' exudate containing tumour cells. At one point the origin of the growth from the external nuclear layer can be made out.

The choroid is invaded by cells at one place near the ora serrata. The central part of the vitreous chamber (about $2 / 3$ of the whole) is occupied by growth. It is a neuro-epithelioma containing many rosette formations. Much of the tumour is necrotic but a large part stains well. The optic nerve is intact behind the lamina cribrosa, but in front of this there is invasion by neuro-epithelioma cells.

Right Eye.-Sections show this to be a very degenerated eye with much congestion in the ciliary body and choroid. There is a considerable amount of calcareous degeneration posteriorly in the choroid, and a few small (early) areas in the ciliary body. The retina is completely detached and folded up. There is no sign of any neoplasm.

CASE XI. Retinoblastoma-uniocular-optic nerve not involved. In good health 8 months after removal:-John M., aged 2 years. Patient of Dr. A. J. Mooney, was admitted on August 5, last. A diagnosis of glioma in the left eye was made and the eye removed.

\section{Microscopic Examination}

The cornea is normal. The anterior chamber contains some albuminous coagulum. There is a peripheral anterior synechia on one side. Both iris and ciliary body are much atrophied. An albuminous coagulum is present in the meshes of the suspensory ligament. Behind the lens there is compressed vitreous. Posterior to this are masses of retinoblastoma cells-endophytum, arising from the outer nuclear layer of the retina.

The anterior part of the growth shows a good deal of calcareous degeneration. In a general way the tumour forms a peripheral circle remaining in relation to the retina-glioma planum-while the centre of the vitreous chamber is occupied for the most part by an albuminous coagulum. There are some haemorrhages present. The retina is detached (not deeply) by an albuminous coagulum containing a few tumour cells. The choroid is atrophied. The optic nerve is not involved.

CASE XII. Retinoblastoma-uniocular - optic nerve - commencing invasion -in good health 4 months later.-Philomena D., patient of Dr. A. J. Mooney, aged $3 \frac{1}{2}$ years, was admitted on October 19, 1942. A glioma retinae of the right eye was diagnosed and the eye was removed on October 22.

The socket and left eye were again examined in November and December and found healthy. 


\section{Microscopic Examination}

Right Eye.-The cornea shows no change of note. The anterior chamber contains an albuminous coagulum. The iris is very atrophied, numerous thin walled vessels being present. The ciliary body also shows a high degree of atrophic change. The vitreous is coagulated behind the lens. The retina is completely detached. The vitreous chamber is filled with retinoblastoma cells-exophytum. There are a few badly staining satellites in contact with the choroid in the sub-retinal space.' The main mass of growth shows many active cells grouped in a circular manner about a central blood vessel. Amidst these are palely staining necrotic areas. Calcareous changes are absent. Here and there in the growth fairly copious haemorrhages are to be seen. The optic nerve shows just commencing invasion by tumour cells, but the lamina cribrosa is not reached. The cut end of the nerve is free of cells.

\section{Comment}

The incidence in this series of 12 patients is 1 in 6,126 , i.e., 0.0017 per cent. This is a rather less frequent incidence than has usually been reported in the literature- 0.04 per cent. to 0.01 per cent. (0.009 per cent. in 40 years at Innsbruck-Badtke).

$A g e .-T w o-t h i r d s$ of the patients were 3 years old, or under, when they came under observation, the ages of the remainder being 8 (seen originally at 1 year 10 months), $3 \frac{1}{2}, 4 \frac{1}{2}$ and 67 years respectively. The last case appears to constitute a record-48 years (Verhoeff), 66 and 35 years (Gerard \& Morel) being the oldest reported.

Sex. -8 males, 4 females. The figures in the literature give about equal numbers affeeted.

Heredity.-In none of these cases was it possible to trace any hereditary factor.

Eyes Involved.-Bilateral 3 cases, unilateral 9.

Trauma.-There was a history of trauma in two cases.

Mortality and Recovery.-Of the twelve cases, 5 are known to be dead, one untraced, presumed dead, and 6 are alive and well for periods varying from 4 years to 4 months since the excision of the eye. Of the fatal cases, the period elapsing between the diagnosis and removal of the eye, and the fatal end, was in Case I seven months, Case II nine months, Case VI ten months, Case VII nine years, Case VIII five months.

Condition of optic nerve and extra ocular extension.-Only one globe, Case VIII, had a demonstrated extra-ocular extension. Cases I and II had microscopically proved invasion of the orbital tissues. 
Case $\mathrm{V}$ is of particular interest in that there was invasion of the optic nerve, as far as the lamina cribrosa, with recovery, the patient being in good health $3 \frac{1}{2}$ years later ( 3 years being generally regarded as the length of time necessary before a cure can be regarded as having taken place).

All the cases with optic nerve involvement outside the lamina cribrosa died.

Tumour Type.-There were 11 cases of retinoblastoma of which 5 have died and one of neuro-epithelioma (alive 8 months after operation). Parkell and Benedict in a review of 16 traced cases of retinoblastoma, found only 12.5 per cent. had a good result, while 62.5 per cent. of neuro-epitheliomas in a series of 16 traced cases, had a good result. Badtke in a review of the glioma cases at Innsbruck from 1900-1939 (14 cases) considered the chance of cure from 50 per cent. to 60 per cent. He put the recovery figure in the bilateral cases at 33 per cent. All the bilateral cases in the Royal Victoria Eye and Ear Hospital series were fatal.

In conclusion I would like to tender my sincere thanks to my colleagues on the staff, for their generous co-operation in the matter of pathological material from and clinical information on, these cases.

I would also like to express my appreciation of the help given by Miss Connor, our Almoner, in "follow ups" and by Miss McQuaid in the collection of statistical data.

\section{ANNOTATION}

\section{Blind Painful Eyes}

We believe it to be a sound rule of practice that blind painful eyes should be enucleated. Especially should this be so if one does not know and cannot see what is the matter inside the eye. A highly congested eye with turbidity of the media may show a dull yellow reflection in the depths of the vitreous. It may be an inflammatory condition and if one is led away by this hypothesis into eviscerating the eye rather than removing it in toto, one must not be surprised if one later finds that there is a new growth steadily increasing in the socket. Such a case would hardly be one of every day occurrence, but perhaps once or twice in a lifetime of practice it might occur. We have always held the opinion that one learns more from failures, our own as well as those of others, than from 